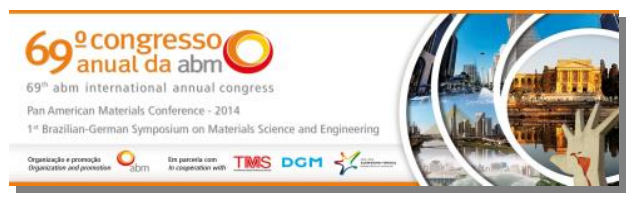

Tema: Produtos: Materiais cerâmicos, compósitos e poliméricos

\title{
DESENVOLVIMENTO E CARACTERIZAÇÃO DE COMPÓSITOS DE MATRIZ POLIMÉRICA (PLGA/PHB) COM FOSFATO DE CÁLCIO BIFÁSICO PELO MÉTODO SOLVENTE CASTING*
}

\author{
Clara Lana Bispo Fidelis ${ }^{1}$ \\ Laís Henriques Figueiredo Coura Ferreira ${ }^{1}$ \\ Layla Mosqueira Moura² \\ Sidney Nicodemos da Silva ${ }^{3}$ \\ Sarah de Morais Bispo Fidelis ${ }^{4}$
}

\section{Resumo}

Nos últimos anos, um grande destaque na área dos biomateriais tem sido dado aos compósitos produzidos a partir de fosfatos de cálcio e biomateriais poliméricos, uma vez que podem ser empregados eficazmente em substituições do sistema ósseo e cartilaginoso. Este trabalho teve por objetivo desenvolver filmes poliméricos a partir de blendas entre dois polímeros biodegradáveis: o PLGA e o PHB, associadas ao BCP na forma de material particulado. Foram produzidas e caracterizadas duas formulações, $50 / 50$ e $70 / 30$ de PLGA e PHB, respectivamente. Em cada formulação dessas blendas foram introduzidas $10 \%$ e $25 \%$ de BCP, em relação à massa da matriz polimérica. Os compósitos foram processados pelo método Casting, sendo obtidos os compósitos pela evaporação do solvente utilizado - clorofórmio. É possível observar pela microscopia eletrônica (MEV) que as partículas de BCP formam uma fase dispersa em torno da matriz polimérica. A combinação destes materiais promoveu uma melhoria na performance mecânica dos compósitos. A conjugação de polímeros e biocerâmicas garantem elasticidade associada ao material polimérico, enquanto 0 BCP promove o aumento da rigidez e resistência à tração. Análises físico-químicas (DSC e DRX) demonstram a possibilidade de existir uma interface difusa entre os polímeros e a biocerâmica. Estes filmes parecem apresentar grande potencial para obtenção de biomateriais para substituições osteocondreais e/ou como membranas reabsorvíveis do periósteo.

Palavras-chave: Biomateriais; Compósitos; Reparos ósseos.

\section{DEVELOPMENT AND CHARACTERIZATION OF COMPOSITES OF POLYMER MATRIX (PLGA / PHB) WITH BIPHASIC CALCIUM PHOSPHATE BY THE METHOD SOLVENT CASTING}

\section{Abstract}

In recent years, a large emphasis in the area of biomaterials has been given to the composites produced from calcium phosphates and polymeric biomaterials, since it can be used effectively in bone system and cartilage replacement. This work aimed to develop polymer films from blends between two biodegradable polymers: PLGA and PHB associated with the BCP in the form of particulated matter. Were produced and characterized two formulations, 50/50 and 70/30 PLGA and $\mathrm{PHB}$, respectively. In each of these blend formulation have been introduced $10 \%$ and $25 \% \mathrm{BCP}$ in relation to the mass of polymer matrix. The composites were processed by casting method, the composites were obtained by evaporating of the solvent used - chloroform. It can be observed by electron microscopy (SEM) that BCP particles form a dispersed phase around the polymer matrix. The combination of these materials has promoted an improvement in the mechanical performance of the composite. The combination of polymers and bioceramics ensure elasticity associated with the polymeric material, while the BCP promotes an increase in hardness and tensile strength. Physicochemical analyzes (DSC and XRD) demonstrated the possibility of a diffuse interface between the polymers and bioceramics. These films appear to have great potential for obtaining bony and cartilaginous replacements biomaterials and/or as reabsorbable membranes of the periosteum.

Keywords: Biomaterials; Composites; Bone replacements.

1 Graduanda em Engenharia de Materiais, bolsista de iniciação científica, Depto. de Engenharia de Materiais, Centro Federal de Educação Tecnológica de Minas Gerais (CEFET-MG), Belo Horizonte, MG, Brasil.

2 Graduada em Ciências Biológicas, bolsista de mestrado em Engenharia de Materiais, Depto. de Engenharia de Materiais, CEFET-MG, Belo Horizonte, MG, Brasil.

3 Doutor em Engenharia Metalúrgica e de Minas, Professor, Departamento de Engenharia de Materiais, CEFETMG, Belo Horizonte, MG, Brasil.

4 Graduanda de Medicina, voluntária de iniciação científica, Universidade Federal de Minas Gerais, Belo Horizonte, MG, Brasil.

\footnotetext{
* Contribuição técnica ao 69 Congresso Anual da ABM - Internacional e ao $14^{\circ}$ ENEMET - Encontro Nacional de Estudantes de Engenharia Metalúrgica, de Materiais e de Minas, 21 a 25 de julho de 2014, 


\section{INTRODUÇÃO}

A necessidade de reparos ósseos cresce a cada ano devido ao grande número de acidentes e da população que envelhece exponencialmente. Os enxertos naturais foram, por muito tempo, considerados quase que em sua totalidade, única opção para estas aplicações clínicas. No entanto, esses enxertos ósseos por vezes apresentam certo grau de rejeição e/ou falhas [1]. Recentemente com o desenvolvimento intensivo das Engenharias de Reabilitação e de Tecidos, novos biomateriais foram aprimorados com o objetivo de suprir essa forte demanda clínica.

Entre esses novos biomateriais, destacam-se os compósitos formados de fosfatos de cálcio com outros biomateriais poliméricos, devido sua biocompatibilidade ou satisfatória resposta biológica [2]. Esses compósitos apresentam de uma maneira geral uma matriz polimérica biodegradável com fases dispersas de biocerâmica (apatitas). Essa característica mimetiza o tecido ósseo, composto basicamente de hidroxiapatita e colágeno [1].

Durante várias décadas, os compósitos processados com os fosfatos de cálcio e o poli L-ácido láctico-co-ácido glicólico (PLGA) têm sido indicados para aplicações ortopédicas. De uma forma geral esses biomateriais poliméricos empregados na Engenharia de reabilitação apresentam biocompatibilidade para vários tipos de tecidos (duros, cartilagem e moles), porém suas propriedades mecânicas (biofuncionalidade) são bastante limitadas em relação aos tecidos calcificados naturais. Por isso a necessidade de adição de apatitas, para incrementar a performance sob solicitações mecânica do compósito no meio fisiológico [1]. A fase orgânica desse compósito propicia elasticidade, enquanto a fase inorgânica por sua vez, eleva a resistência à tração [1]. Além disso, a superfície hidrofóbica dos filmes poliméricos dificulta a adesão celular como demonstrados nos ensaios in-vitro e in-vivo, enquanto a hidroxiapatita sintética estimula a adesão e o crescimento dos osteoblastos, melhorando a resposta material-hospedeiro [1,3,4].

Assim é fundamental incorporar aspectos de síntese ou fabricação destes compósitos, seguindo a abordagem de ciência dos materiais que busca entender e otimizar parâmetros de processamento que modificam a microestrutura, e possam incrementar as propriedade biológicas e/ou mecânicas. Todavia, o efeito da incorporação de materiais particulados (grânulos, pós ou coloides) parece favorecer o desempenho mecânico e também biológico do PLGA/PHB.

Neste trabalho, foram desenvolvidos filmes de PLGA (poli L-ácido láctico-co-ácido glicólico) e PHB (poli (3-hidroxibutirato)) associados ao BCP (fosfato de cálcio bifásico) pelo método de processamento gel casting (evaporação do solvente orgânico). Buscouse ainda neste trabalho descreve o Estado da Arte sobre os desafios e inovações em matéria de dispersão do BCP sobre compósitos de matriz polimérica, viabilizando no futuro utilizações destes filmes como biomateriais para enxertos, membranas ou scaffolds em reparos dos tecidos osteocondreais.

Tanto o PLGA quanto o PHB são polímeros reabsorvíveis e produzem ácidos com o decorrer de sua biodegradação. Os seus produtos de degradação no meio fisiológico são reabsorvidos e excretados e, portanto, não acumulam no organismo [5]. O objetivo da associação desses dois polímeros se deve a constatação de que a obtenção de blendas ou misturas mecânicas entre dois polímeros biodegradáveis pode ser utilizada de forma eficaz para modificar as propriedades físicas e mecânicas não presentes individualmente em cada um separadamente [6].

O BCP (constituído de 90\% hidroxiapatita e 10\% $\beta$-trifosfato de cálcio) é uma cerâmica bifásica tida como bioativa. Seu comportamento mecânico, ainda que frágil, garante dureza ao compósito [1]. Além disso, a degradação do material em meio biológico é

* Contribuição técnica ao 69 Congresso Anual da ABM - Internacional e ao 14ํㅡㄹ ENEMET - Encontro Nacional de Estudantes de Engenharia Metalúrgica, de Materiais e de Minas, 21 a 25 de julho de 2014, 
acelerada pelo BCP devido a sua osteocondutividade e capacidade de controlar a acidez causada pela degradação dos polímeros $[3,7,8]$.

Neste trabalho foram desenvolvidas quatro proporções de filmes com diferentes concentrações dos polímeros (50/50 e 70/30 de PLGA/PHB) e diferentes porcentagens em massa de BCP (10 e $25 \%$ ).

\section{MATERIAIS E MÉTODOS}

\subsection{Materiais}

\subsubsection{Poli L-ácido láctico-co-ácido glicólico (PLGA)}

O (poli L-ácido láctico-co-ácido glicólico) ou PLGA foi adquirido na empresa PURAC Biochem by Gorinchem (Holanda) com certificado EMEA (órgão homologador europeu para a área de saúde). A proporção entre os monômeros constituintes do polímero utilizado é $80 / 20$ (80\% de ácido lático e $20 \%$ de ácido glicólico).

\subsubsection{Poli (3-hidroxibutirato) (PHB)}

O poli (3-hidroxibutirato) ou PHB foi fornecido pelo Departamento de Química do CEFET-MG. Esse polímero, na forma de material particulado, foi fabricado pela empresa PHB Industrial através de uma rota de síntese utilizando a fermentação seguida de purificações do produto e tem como nome comercial Biocycle.

\subsubsection{Clorofórmio}

O Clorofórmio P.A. foi forrnecido pela empresa Synth Química, foi utilizado como solvente para a dissolução dos polímeros para a produção dos filmes e blendas.

\subsubsection{Hidroxiapatita (HA) e Beta Trifosfato de Cálcio (BCP)}

O BCP foi fornecido pela empresa Inside Materiais Avançados, tendo proporção de fase $90 \%$ HA e 10\% $\beta$-TCP, com distribuição de tamanho de partículas entre 37 e 150 $\mu \mathrm{m}$.

\subsection{Métodos}

\subsubsection{Obtenção de filmes 50/50 (PLGA/PHB) com BCP}

Um grama de PLGA foi dissolvido em $100 \mathrm{~mL}$ de clorofórmio e mantido sob agitação magnética por duas horas. O mesmo procedimento foi realizado com o PHB, no entanto, devido à baixa dissolução deste polímero a suspensão foi aquecida a $50^{\circ} \mathrm{C}$ por cerca de duas horas. Em seguida, as duas soluções foram vertidas em um único béquer contendo 0,2 ou 0,5 gramas de BCP. A suspensão resultante deste processo de mistura foi mantida sob agitação magnética com aquecimento por mais doze horas. Após esta etapa de homogeneização da mistura e evaporação inicial do solvente, a mesma foi vertida em uma placa de petri até a formação do filme. Com isso, os filmes foram levados à estufa à $40^{\circ} \mathrm{C}$ por 24 horas para ocorrer a evaporação de vestígios de clorofórmio.

\subsubsection{Obtenção de filmes 70/30 (PLGA/PHB) com BCP}

Um procedimento semelhante foi executado para obtenção dos filmes como a formulação pretendida de 70/30, PLGA e PHB respectivamente. Assim foram pesadas 1,4 gramas de PLGA sendo a seguir dissolvido em $140 \mathrm{~mL}$ de clorofórmio. Posteriormente, 0,6 gramas de PHB foram dissolvidos em $60 \mathrm{~mL}$ de clorofórmio (esta suspensão também foi aquecida a $50^{\circ} \mathrm{C}$ por $2 \mathrm{~h}$ para solubilização do $\mathrm{PHB}$ ). A formação

\footnotetext{
* Contribuição técnica ao 69 Congresso Anual da ABM - Internacional e ao 14ํㅡㄹ ENEMET - Encontro Nacional de Estudantes de Engenharia Metalúrgica, de Materiais e de Minas, 21 a 25 de julho de 2014, 
dos filmes ocorreu de forma análoga à síntese descrita acima. Com a formação dos filmes, esses foram levados à estufa à $40^{\circ} \mathrm{C}$ por 24 horas para ocorrer a evaporação de vestígios de clorofórmio.

\subsubsection{Caracterização dos filmes de PLGA/PHB com BCP}

Foram realizados ensaios físico-químicos com Microscopia Eletrônica de Varredura (MEV) para análise morfológica (superfície e/ou seção fratura com uso de $\mathrm{N}_{2}$ líquido). Um microscópio Shimadzu modelo SSX-550 com espectroscopia de energia dispersiva de raios-X (EDS) foi utilizada para investigação da topografia e composição dos filmes. Também a técnica de Difração de Raio $X$ (DRX) foi utilizada para análise de fases cristalinas, através do equipamento Shimadzu modelo no XRD-7000, operado com corrente de excitação de $30 \mathrm{~mA}$, tensão de aceleração do tubo de raios-X de $40 \mathrm{kV}$ (alvo de cobre). A varredura, teta-teta, ocorreu na faixa de 10 a $80^{\circ}$, com velocidade de $0,5^{\circ} / \mathrm{min}$ e campo de amostragem de $0,02^{\circ}$ (por step). Análises Térmicas Diferenciais (DSC) foram realizadas nos filmes para avaliação do comportamento térmico, sendo utilizado um equipamento Shimadzu.

Foram realizados nos filmes ainda ensaios mecânico de tração (numa máquina universal de ensaios de 1 tonelada-força) e de microdureza Vickers (HV) com 50gf e tempo de 15s, ambos em equipamento Shimadzu.

\section{RESULTADOS E DISCUSSÃO}

\subsection{Análise da Superfície dos Filmes}

Imagens da superfície dos filmes foram capturadas pelo microscópio eletrônico de varredura (MEV) com o objetivo de avaliar possíveis interações formadas durante 0 processamento entre as duas fases poliméricas e as partículas de BCP. É possível perceber que nos filmes com 10\% de BCP formaram-se agrupamentos de partículas, possivelmente devido à distribuição irregular da biocerâmica. Esta dispersão não homogênea podem talvez indicar que a cerâmica possua carga superficiais no pH da suspensão que promovem sua aglutinação, ocasionada pelo níveis do seu potencial zeta, no meio durante a secagem. No caso dos filmes com $25 \%$, há formação de maior quantidade de clusters (aglomerados) de BCP. A Figura 1 mostra as imagens obtidas para ambos compósitos:

\footnotetext{
* Contribuição técnica ao 69 Congresso Anual da ABM - Internacional e ao 14ํㅡㄹ ENEMET - Encontro Nacional de Estudantes de Engenharia Metalúrgica, de Materiais e de Minas, 21 a 25 de julho de 2014, 


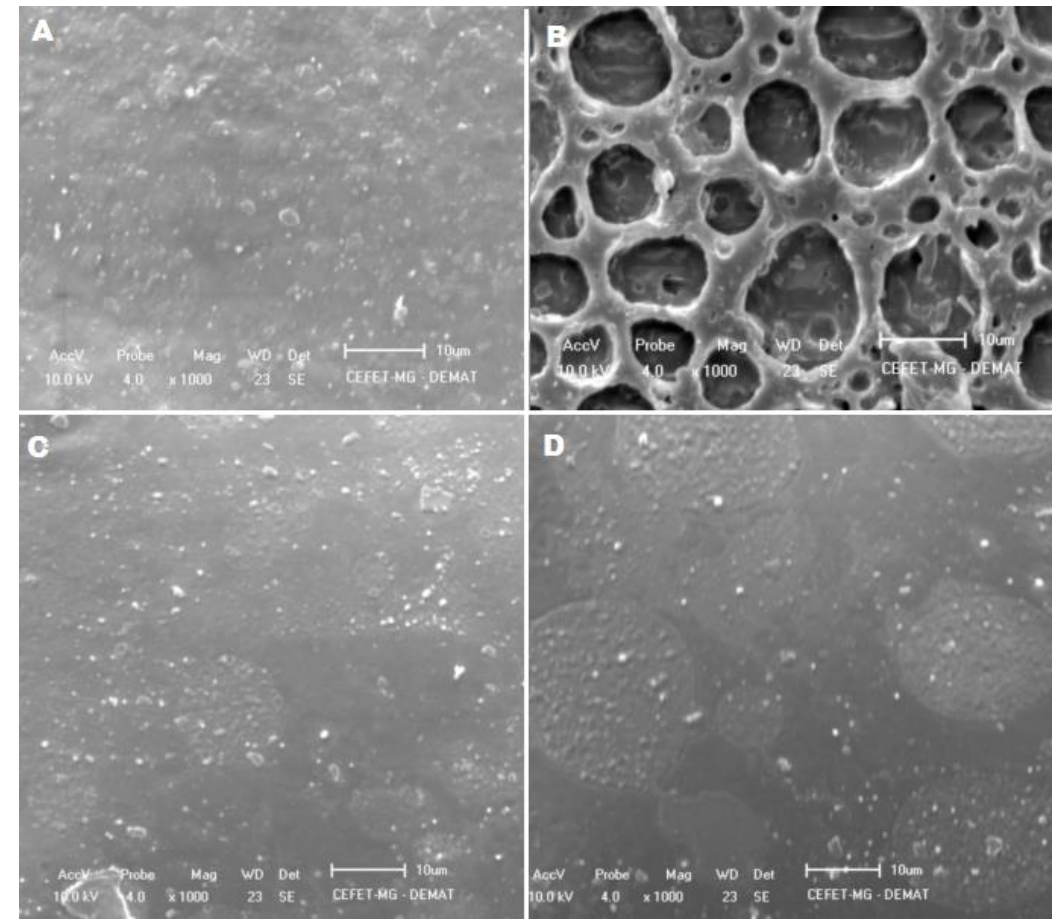

Figura 1. Imagens do MEV dos filmes (a) 50/50 PLGA/PHB 10\% BCP; (b) 50/50 PLGA/PHB 25\% BCP; (c) 70/30 PLGA/PHB 10\% BCP; (d) 70/30 PLGA/PHB 25\% BCP.

Lee et al. [3] obteve filmes semelhantes com a mistura do PLGA/HA com 5, 10 e $15 \%$ em massa de hidroxiapatita $(\mathrm{HA})$ e reportou a existência desses clusters nas concentrações acima de $10 \%$ de HA. Contudo, seus filmes foram feitos apenas PLGA/BCP. Em nosso estudo o PHB, por sua vez, apresenta um papel modificador importante nos filmes, não somente melhorando as propriedades da matriz como também proporcionando uma estrutura de poros como pode ser visto na Figura 1.B ( $50 / 50$ com $25 \%$ de BCP). A seguir também serão mostrados aspectos desta interação entre os constituintes dos compósitos.

\subsection{Análise Térmica Superficial das Blendas de PLGA e PHB}

Anteriormente a produção dos compósitos, houve a produção e caracterização de filmes puros de PLGA, PHB e da blenda 50/50, seguida a rota descrita sem a adição do BCP. Embora objetivo deste trabalho, fossem à adição de BCP nos dois filmes para análise de seu comportamento e estrutura, alguns resultados anteriores norteiam a escolha dos parâmetros de processamento e formulações de controle.

A Figura 2 mostra o perfil comparativo da análise térmica diferencial dos filmes puros de PHB e PLGA e de sua blenda 50/50. É possível observar que os perfis encontrados nos filmes puros se assemelham ao perfil da blenda. Essa análise pode ser indicativa da miscibilidade parcial entre os polímeros na proporção utilizada. Ainda que o ensaio não tenha sido repetido para os compósitos polímeros/BCP, é esperada uma provável formação de uma nova interface $\mathrm{BCP} /$ matriz proveniente de possíveis reações superficiais entre estes materiais. 

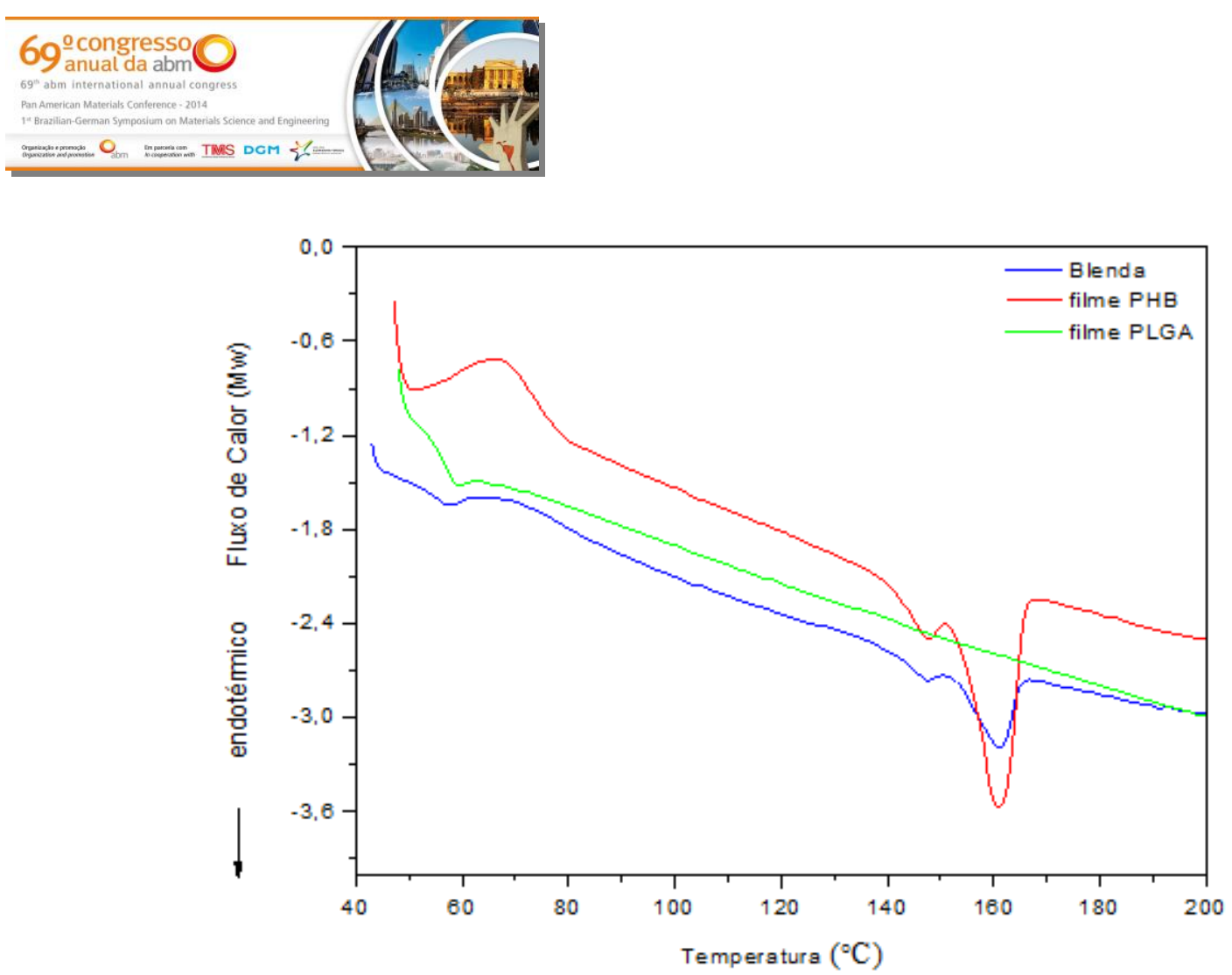

Figura 2. DSC dos filmes puros de PLGA, PHB e sua blenda 50/50.

A comparação entre filmes puros e a blenda mostra que as mesmas temperaturas de reações exotérmica e endotérmicas estão presentes, o que reforça a hipóteses de validade da regra da mistura com solubilização parcial das matérias-primas.

\subsection{Análise de Cristalinidade por Difração de Raios-X (DRX)}

A Figura 3 apresenta o difratograma dos filmes puros de PLGA, PHB e as blendas 50/50 e 70/30. É possível observar que o PHB é um polímero semicristalino com picos de cristalinidade entre $10^{\circ}$ e $30^{\circ}$. O PLGA, por sua vez, é um polímero predominantemente amorfo, ou seja sem picos cristalinos e com o centro do álamo amorfo em torno de $18^{\circ}$. Já as blendas apresentam picos cristalinos semelhantes aos do PHB, com centro do espalhamento (ou porção) amorfo semelhante ao do PLGA. Neste caso, como também já identificado na análise térmica (DSC) houve a ocorrência e distribuição das fases obedecendo às proporções estabelecidas pela regra da mistura.

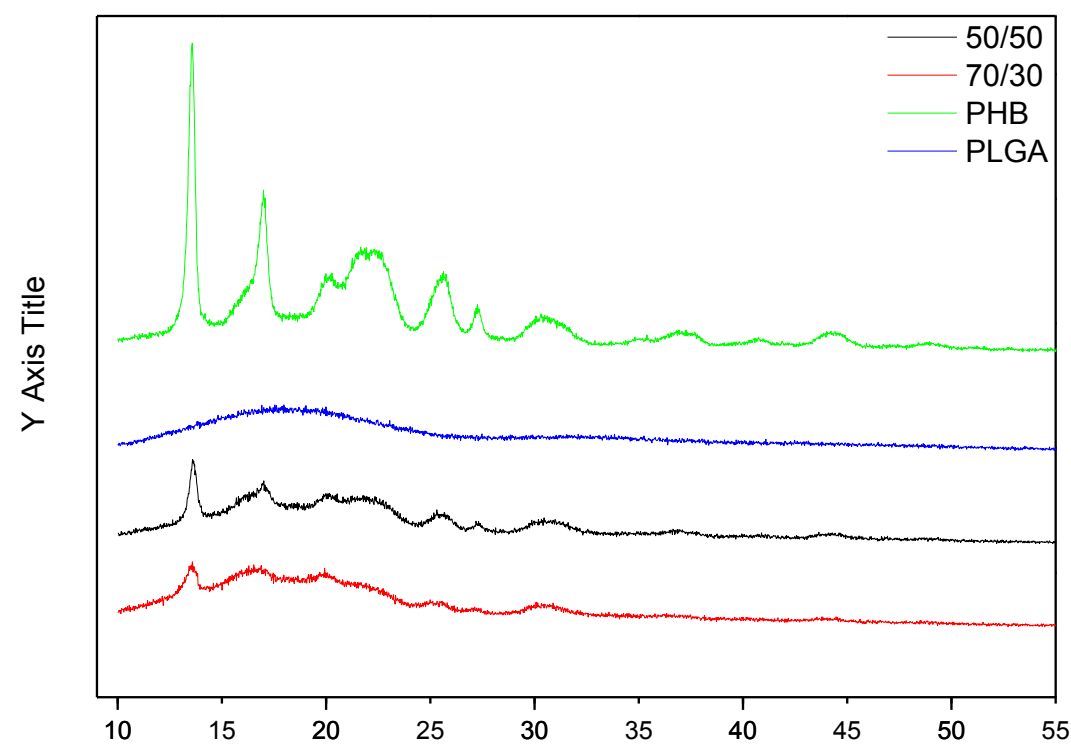

Figura 3. DRX dos filmes puros de PLGA, PHB e suas blendas $50 / 50$ e $70 / 30$.

* Contribuição técnica ao 69 Congresso Anual da ABM - Internacional e ao 14ํㅡㄹ ENEMET - Encontro Nacional de Estudantes de Engenharia Metalúrgica, de Materiais e de Minas, 21 a 25 de julho de 2014, 
A partir dessas análises (DSC e DRX) de extrema importância para entender a formação da microestrutura dos filmes puros e blendas, é que se iniciou a formulação dos compósitos polímeros/BCP.

A Figura 4 apresenta os dois difratogramas dos filmes 50/50 de PLGA/PHB com as duas proporções de BCP $(10 \%$ e $25 \%)$. A seta verde indica o pico cristalino característico do PHB. Os demais picos são característicos do BCP, ou seja, da hidroxiapatita (HA) ou do $\beta$-trifosfato de cálcio, que são biocerâmicas com elevado índice de cristalinidade. A curva azul apresenta maior índice de cristalinidade, uma vez que possui maior massa de BCP. A Tabela 1 mostra os valores de cristalinidade (em porcentagem) calculada através do aparelho.

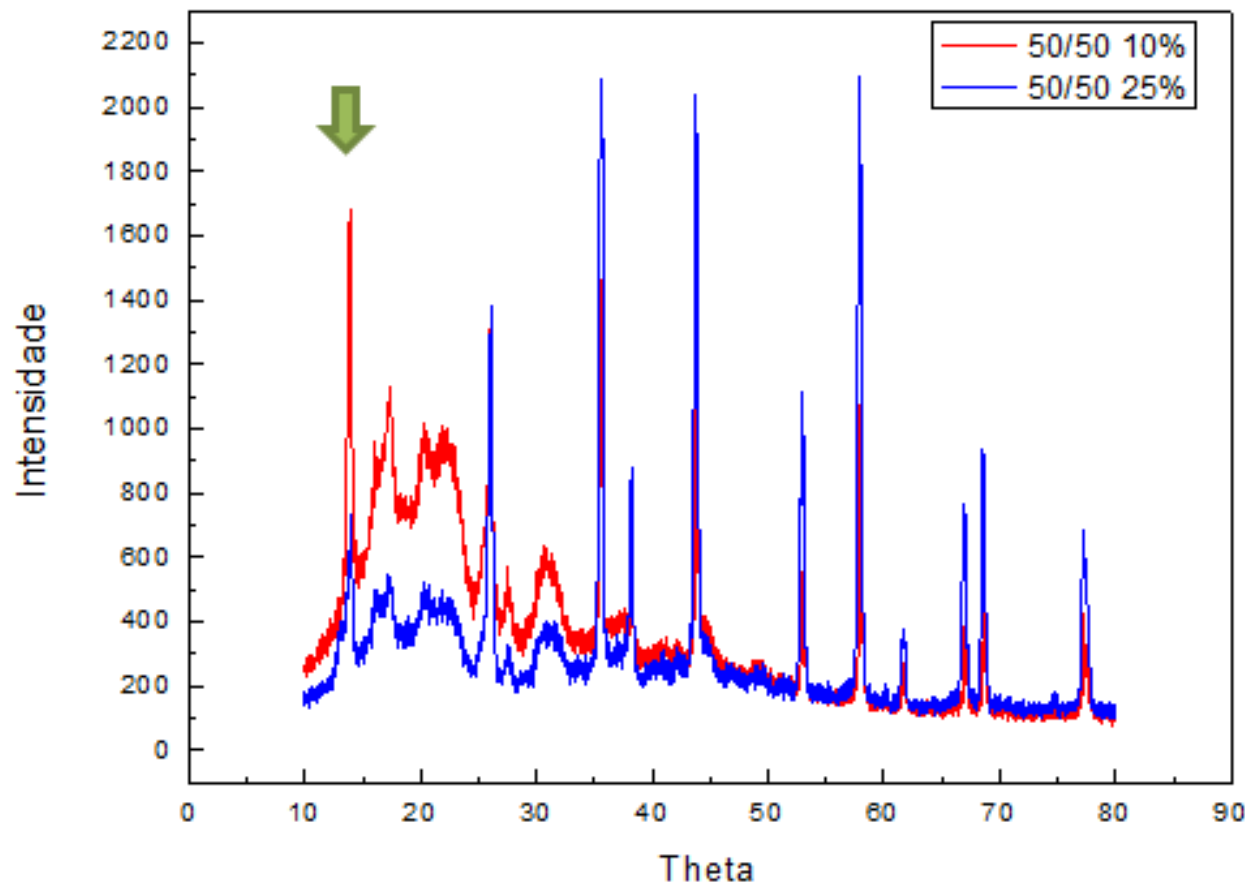

Figura 4. DRX dos filmes 50/50 PLGA/PHB com BCP.

A Figura 5 contém os difratogramas dos filmes 70/30 de PLGA/PHB com adição de BCP. Novamente observa-se o pico cristalino característico do PHB (representado pela seta verde) e os picos da HA e do $\beta$-trifosfato de cálcio (BCP). A Tabela 1 também mostra os valores de cristalinidade (em porcentagem) calculada através do aparelho esta formulação. 


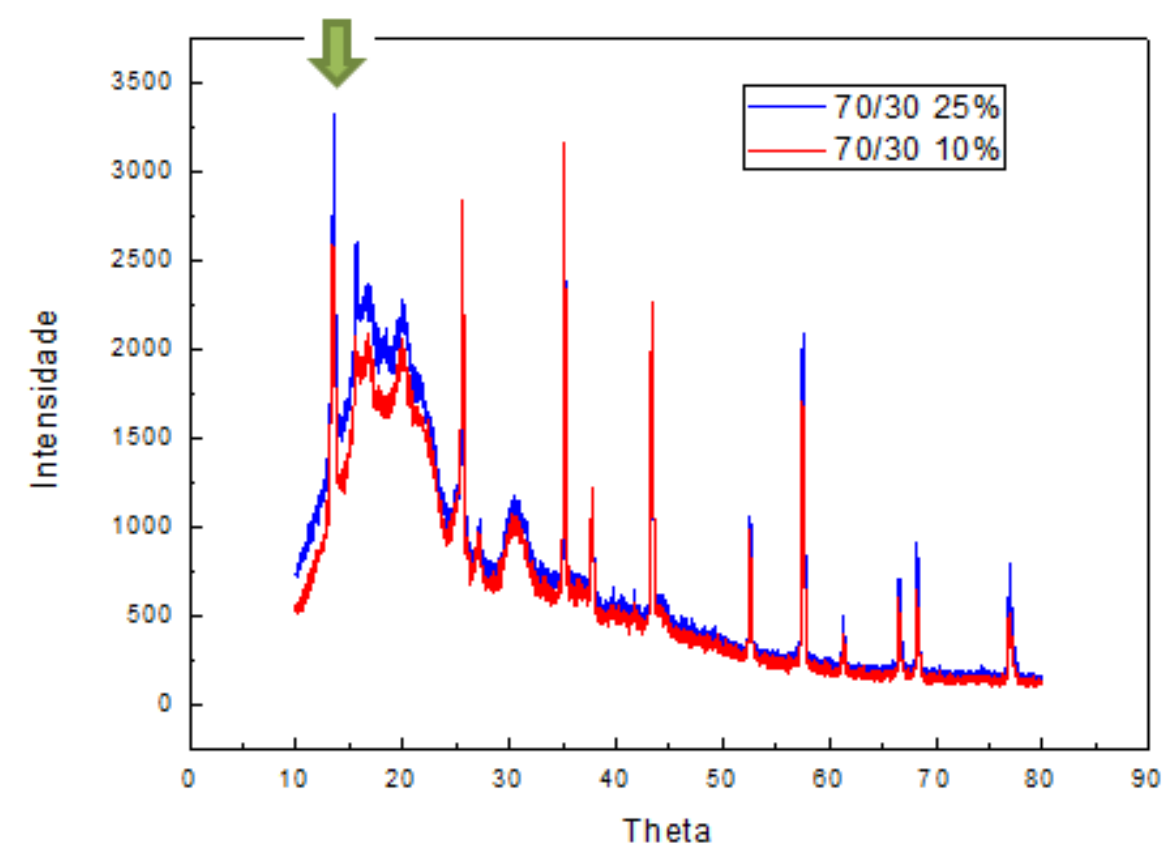

Figura 5. DRX dos filmes 70/30 PLGA/PHB com BCP.

Observa-se no caso da Figura 5 que o efeito associado a maior presença do PLGA na matriz polimérica aumentou a contribuição amorfa no DRX de ambos compósitos 10 e $25 \%$ de BCP.

Tabela 1. Valores de cristalinidade dos filmes

\begin{tabular}{|c|c|c|c|c|}
\hline Filme & $50 / 50+10 \%$ & $50 / 50+25 \%$ & $70 / 30+10 \%$ & $70 / 30+25 \%$ \\
\hline $\begin{array}{l}\text { Porcentagem de } \\
\text { cristalinidade }\end{array}$ & 25,2 & 47,8 & 24,8 & 23,3 \\
\hline
\end{tabular}

Os valores de cristalinidade dos filmes $70 / 30$ com $10 \%$ e $25 \%$ de BCP estão muito próximos um do outro. $O$ que pode ser explicado talvez pela deconvolução do álamo amorfo e as fases cristalinas nas proporções estudadas, ou seja, a energia difratada sofreu um espalhamento maior em torno centro da interferência construtiva (18\%) devido ao grande percentual de PLGA nestes filmes.

\subsection{Ensaios Mecânicos}

Os ensaios mecânicos tiveram por objetivo investigar as modificações nas propriedades mecânicas dos filmes compósitos na medida em que se adiciona uma segunda fase cerâmica. Sabe-se que as blendas poliméricas possuem uma boa elasticidade, enquanto a cerâmica apresenta como característica mecânica: elevada rigidez (ou módulo de elasticidade), razoável resistência à tração, e baixa tenacidade à fratura, indicando tratar-se de um material frágil.

\subsubsection{Ensaio de tração}

Os ensaios de tração foram realizados apenas em amostras dos filmes de concentração 50/50 de PLGA/PHB, e com 10\% e 25\% de BCP. A Tabela 2 a seguir apresenta valores extraídos a partir de 5 (cinco) medições em corpos de prova de seção reduzida. Os valores das médias e dos desvios padrões para a tensão no limite

\footnotetext{
* Contribuição técnica ao 69ํ Congresso Anual da ABM - Internacional e ao 14ํㅡㄹ ENEMET - Encontro Nacional de Estudantes de Engenharia Metalúrgica, de Materiais e de Minas, 21 a 25 de julho de 2014, 
de resistência (tensão máxima), deformação na ruptura e módulo de Young, indicam que, o efeito predominante da matriz polimérica teve maior significância sobre estes resultados mecânico. Apesar da microestrutura (obtida por MEV) e as proporções das fases (DRX) indicam uma tendência de validação da regra da mistura também estes casos, isto não foi confirmado.

Tabela 2. Valores de tensão, deformação e módulo de Young

\begin{tabular}{cccc}
\hline Filme & $\begin{array}{c}\text { Tensão máxima } \\
(\mathrm{MPa})\end{array}$ & $\begin{array}{c}\text { Deformação na } \\
\text { Ruptura }(\%)\end{array}$ & $\begin{array}{c}\text { Módulo de Young } \\
(\mathrm{GPa})\end{array}$ \\
\hline $50 / 50+10 \%$ & $23,9 \pm 1,5$ & $12,0 \pm 2,2$ & $16,67 \pm 0,20$ \\
\hline $50 / 50+25 \%$ & $21,4 \pm 1,9$ & $14,2 \pm 1,2$ & $13,4 \pm 1,5$ \\
\hline
\end{tabular}

Velocidade da máquina de tração: $5 \mathrm{~mm} / \mathrm{seg}$.

Como o efeito da matriz observado na DRX para formulação $70 / 30 \mathrm{com}$ o $\mathrm{BCP}$ foi muito pronunciado, entende-se que os cálculos dos ensaios nestes filmes também apresentariam possivelmente esta interferência da matriz na proporcionalidade de cada fase. Assim seu efeito ponderado nas propriedades mecânicas, nesta concentração de fases, resulta numa menor proporção de fases cristalinas ocorridas do percentual de PLGA, e nas concentrações de BCP, menor melhoria das propriedades neste quesito. Constata-se que a tensão máxima das amostras com concentração $10 \%$ de BCP é relativamente superior às das amostras com concentração de $25 \%$ de BCP (mesmo que os desvios padrões aparentemente se superponham). Apesar das cerâmicas conferirem ao filme maior resistência, os aglomerados -ou clusters- de BCP formados na concentração de $25 \%$ causam fragilização na microestrutura do filme, gerando linhas de fratura na matriz polimérica. Durante a tração, essas linhas são responsáveis por rupturas, diminuindo, portanto, as forças demandadas para romper esses filmes.

De acordo com Lee et al. [4] as concentrações de 5 e 10\% em massa de hidroxiapatita apresentaram um melhoramento das propriedades mecânica em relação ao filme controle (PLGA puro), enquanto na concentração acima de 10\% houve decaimento da tensão máxima admissível. Estes autores concluem que concentrações mais baixas ( 5 e $10 \%$ ) se mostram adequadas para substituições cartilaginosas devido a suas propriedades mecânicas.

\subsubsection{Dureza}

Os ensaios de microdureza Vickers (HV 0,05) foram realizados com o objetivo de se verificar o aumento da dureza esperado causado pela adição de BCP em uma matriz polimérica. Na concentração de 50/50 de PLGA/PHB com BCP, essa estimativa foi confirmada, pois o aumento da massa cerâmica causa um aumento na dureza.

Contudo, os valores de dureza nas amostras de concentração 70/30 com adição do BCP, não estão de acordo com essa análise, ou seja: há uma diminuição no valor da dureza. A Tabela 3 apresenta os valores das médias com os desvios padrões das medições realizadas em ambas as amostras:

Tabela 3. Valores de microdureza Vickers dos filmes (HV 0,05)

\begin{tabular}{lcccc}
\hline Filme & $50 / 50+10 \%$ & $50 / 50+25 \%$ & $70 / 30+10 \%$ & $70 / 30+25 \%$ \\
\hline $\begin{array}{l}\text { Média e } \\
\text { desvio padrão }\end{array}$ & $7,41 \pm 0,73$ & $8,86 \pm 0,90$ & $6,05 \pm 0,34$ & $4,57 \pm 0,64$ \\
\hline
\end{tabular}

Os resultados nas amostras $70 / 30$ com $25 \%$ de BCP podem ser justificado pela formação de aglomerados ou clusters que fragilizam a matriz e reduzem os valores

\footnotetext{
* Contribuição técnica ao 69ํ Congresso Anual da ABM - Internacional e ao 14ํㅡㄹ ENEMET - Encontro Nacional de Estudantes de Engenharia Metalúrgica, de Materiais e de Minas, 21 a 25 de julho de 2014, 
experimentais encontrados para a tensão máxima. Isto é, a cerâmica possivelmente estava concentrada em determinados espaços dos filmes, e como o ensaio de dureza permite uma análise localizada, o penetrador apenas atingiu (aleatoriamente) locais de baixa concentração de BCP.

\section{CONCLUSÃO}

Observou que a microestrutura, morfologia e composição das fases obedecem à regra de Gibbs para as misturas de fases. O PHB apresentou um papel modificador importante nos filmes, melhorando as propriedades da matriz e proporcionando 0 aparecimento de uma estrutura de poros como pode ser visto por MEV nas amostras com 50/50 e $25 \%$ de BCP, sugeridos no futuro seu aproveitamento como um scaffold para engenharia de tecido. Embora, os resultados mecânicos não foram muito diferentes a amostra que apresentou na média melhor desempenho foi a 50/50 e $25 \%$ de BCP. Acredita-se que estes filmes apresentaram um potencial satisfatório para obtenção de biomateriais em substituições osteocondreais e/ou como membranas reabsorvíveis do periósteo

\section{Agradecimentos}

Ao CNPq (Centro Nacional de Desenvolvimento Científico e Tecnológico), pela bolsa de iniciação científica contemplada (PIBIC edital № 56/13). Ao Departamento de Química do CEFET-MG, pela disponibilização de laboratórios, materiais e equipamentos.

\section{REFERÊNCIAS}

1 Zhou, H., et al. Fabrication aspects of PLA-CaP/PLGA-CaP composites for orthopedic applications: A review. ActaBiomaterialia, USA, v.8, p.1999-2016, feb. 2012. Ignjatovic, N.; Ajdukovic, Z.; Uskokovic, D. New biocomposite [biphasic calcium phosphate/poly-DL-lactide-co-glycolide/biostimulative agent] filler for reconstruction of bone tissue changed by osteoporosis. J Mater Sci Mater Med 2005; 16:621-626.

2 Deng X, Hao J, Wang C. Preparation and mechanical properties of nanocomposites of poly (D,L-lactide) with Ca-deficient hydroxyapatite nanocrystals. Biomaterials 2001;22:286773.

3 Lee JB, Lee SH, Yu SM, Park JC, Choi JB, Kim JK. PLGA scaffold incorporatedwith hydroxyapatite for cartilage regeneration. Surf Coat Technol 2008;202:5757-61.

Vooren, C. VAN. Water permeability of PLGA and PHB enriched with additives. 2012. Master thesis - Chent University, Belgium, 2012.

4 Fwu-long, M., et al. Chitin/PLGA blend microspheres as a biodegradable drug-delivery system: phase-separation, degradation and release behavior. Biomaterials, Taiwan, v.23, p.3257-3267, feb. 2002.

5 Vallet-Regi M, Gonzalez-Calbet JM. Calcium phosphates as substitution of bone tissues. Prog Solid State Chem 2004;32:1-31.

6 Quental, A. C. et al. BLENDAS DE PHB E SEUS COPOLÍMEROS: MISCIBILIDADE E COMPATIBILIDADE. 2. ed. Campinas - Sp, Brasil: Química Nova, 2010. 438-446 p.

7 Ulery, B.D. et al. Biomedical applications of biodegradable polymers. Journal of Polymer Science Part B: Polymer Physics, v. 49, p. 832-864, Apr. 2011.

8 Ebrahimian-Hosseinabadi, M. et al. Evaluating and Modeling the Mechanical Properties of the Prepared PLGA/nano-BCP Composite Scaffolds for Bone Tissue Engineering. J Mater Sci Mater Med 2011; 27(12), 1105-1112.

\footnotetext{
* Contribuição técnica ao 69 Congresso Anual da ABM - Internacional e ao 14 ENEMET - Encontro Nacional de Estudantes de Engenharia Metalúrgica, de Materiais e de Minas, 21 a 25 de julho de 2014, 